\title{
Facts about Wildlife Diseases: Bats and Coronaviruses ${ }^{1}$
}

\author{
Holly K. Ober and Samantha M. Wisely²
}

Some unusual physical adaptations allow bats to harbor viruses that cause no harm to themselves but can cause grave illness in humans. Transmission of these pathogens from bats to humans can occur when humans have close interactions with bats and contact with their bodily fluids. A number of strategies could reduce the likelihood of bat viruses crossing over to humans, such as restricting the harvest of bats for food, curtailing live wildlife markets, enforcing regulations on illegal wildlife trade, and limiting deforestation and cave vandalism to reduce movement of bats into close proximity to humans.

Recently, misguided attempts to preserve human health have led to persecution of bats. In fact, however, what will keep people healthy is to protect bats and their habitat. Enhancing efforts to protect bat roosts can reduce the likelihood of future zoonotic disease pandemics while at the same time increasing the valuable contributions bats provide to natural ecosystems and the benefits they provide to people. Protecting bat roosts can benefit people economically because bats provide valuable natural pest reduction services when they consume insects that cause damage to agronomic crops. Protecting bat roosts can also enhance human health by ensuring bats continue to consume mosquitoes responsible for transmitting diseases such as Zika, dengue fever, malaria, and chikungunya. Finally, protecting bat roosts keeps bats safely distanced from people. Destroying their homes merely forces bats into closer proximity to humans.

\section{Bats Don't Get III from Many of the Viruses That Sicken Humans}

Bats have highly specialized immune systems that allow them to harbor viruses without showing signs of illness. For many mammals, including humans, it is not the viral infection that kills but the acute inflammatory response mounted by their immune systems. Bats have evolved ways to inhibit the pro-inflammatory response of their immune systems, so though they get infected by viruses, they suffer no visible signs of disease from those viral infections. Their ability to control the inflammatory responses of their immune systems may also explain bats' relatively long lifespans. Scientists are studying the immune systems of bats to develop strategies to better regulate the inflammation response in humans.

\section{How could bats pass viruses to humans?}

Wildlife pathogens are considered zoonotic when they are transmitted to humans and cause disease. This transmission is called a spillover event, because the virus "spills over" from animal hosts to human hosts (Figure 1). Some zoonotic viruses simply end their transmission cycle when they infect a human (i.e., the human is unable to pass on the virus to other humans). In this case, the human is called a dead-end host. Sometimes, however, the virus evolves a way to transmit among humans, causing a human epidemic. If an epidemic spreads across continents, it is called a pandemic.

1. This document is WEC428, one of a series of the Department of Wildlife Ecology and Conservation, UF/IFAS Extension. Original publication date May 2020. Visit the EDIS website at https://edis.ifas.ufl.edu for the currently supported version of this publication.

2. Holly K. Ober, associate professor of wildlife ecology and wildlife Extension specialist, Department of Wildlife Ecology and Conservation, UF/IFAS North Florida Research and Education Center, Quincy, Florida 32351; and Samantha M. Wisely, professor, Department of Wildlife Ecology and Conservation, UF/IFAS Extension, Gainesville, Florida 32611.

The Institute of Food and Agricultural Sciences (IFAS) is an Equal Opportunity Institution authorized to provide research, educational information and other services

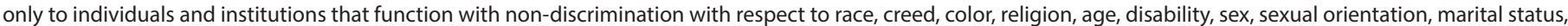

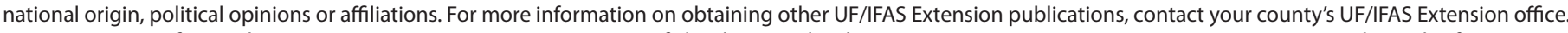
U.S. Department of Agriculture, UF/IFAS Extension Service, University of Florida, IFAS, Florida A \& M University Cooperative Extension Program, and Boards of County Commissioners Cooperating. Nick T. Place, dean for UF/IFAS Extension. 


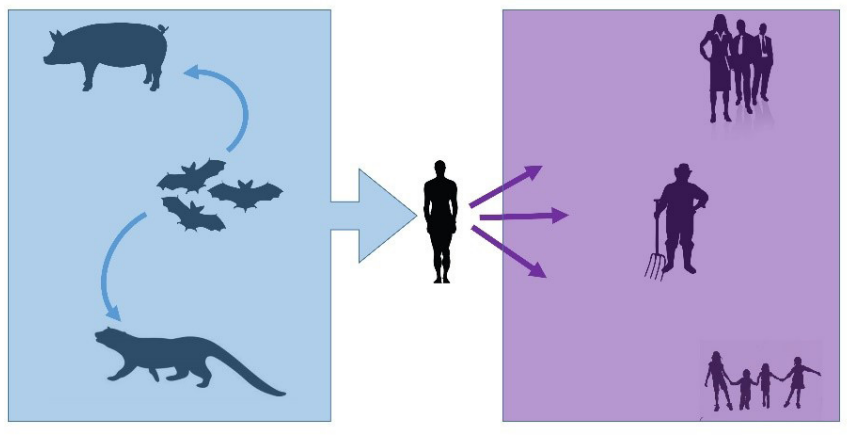

Figure 1. Many viruses naturally circulate within animals (blue); some of these can spill over into humans. These wildlife viruses that infect humans are called zoonotic viruses. The transmission cycle ends for those viruses that humans cannot pass on. However, those viruses that evolve a way to transmit among humans (purple) can cause a human epidemic, and, if the disease spreads across continents, a pandemic.

Credits: Samantha Wisely, UF/IFAS

Because humans are not typically exposed to wildlife viruses, we are susceptible to infection in those rare instances when we are exposed. Clinical illness can then result. Because viruses can mutate quickly, once transmitted to humans, they can rapidly evolve the ability to jump from one human to another without a wildlife host. Human-tohuman transmission can then occur quickly and lead to epidemics or even pandemics.

Unless a virus has already evolved human-to-human transmission abilities, humans can only contract zoonotic viruses when they come into close contact with wildlife. Saliva, urine, feces, and other bodily fluids of an infected animal can transmit viruses to people. Humans could contract viruses by handling infected bats or their bodily fluids. For this reason, protective equipment should be worn when entering structures where bats are known to roost, such as attics or bridges. Professional bat exclusion personnel and researchers who handle bats should consider pre-exposure vaccinations to prevent transmission of rabies from bats to humans.

Wildlife markets, trade in meat from wildlife, called bushmeat, and illegal hunting of wildlife (three instances where humans come into close contact with wildlife) have been implicated in spillover events. Public health and wildlife conservation organizations have called for tightening of restrictions on the bushmeat trade and the closing of all wildlife markets to prevent future spillover of zoonotic diseases into humans.

Close contact between wildlife and humans can also occur when wildlife habitat is destroyed.
Deforestation and suburban sprawl can displace wildlife, including bats. Purposeful vandalism of caves or harvesting of trees used as bat roosts can force bats into closer proximity to humans, which is the phenomenon we want to avoid. Furthermore, displaced bats will be stressed, due to their acute need to find alternative sources of shelter. When stressed, animals produce more virus, increasing the chances of disease transmission to humans. For this reason, people would be far better served if they acted to protect the natural habitats bats need rather than harming those habitats and thereby forcing bats into poor-quality environments. Destroying bats' homes does not eliminate bats. It does make bats more dangerous to people by increasing the bats' viral loads and forcing them to live closer to people.

\section{What kinds of viruses do bats carry?}

Because of their well-adapted immune systems, bats can harbor many types of viruses. Some species of bats are known to carry lyssaviruses including the rabies virus, filiviruses including Ebola and Marburg viruses, and paramyxoviruses, including Nipah and Hendra viruses. In addition, some bats can carry coronaviruses without being afflicted.

There are hundreds of viruses that are classified as coronaviruses, seven of which can cause respiratory infections in humans. Recently, three different types of coronaviruses have caused respiratory disease outbreaks in humans: SARS (Severe acute respiratory syndrome) during 2002-2004, MERS (the Middle East respiratory syndrome) during 2012-present, and COVID-19 during 2019-present. It is believed that the coronaviruses responsible for all three of these disease outbreaks were zoonotic, meaning that the viruses were originally circulating in animals before spilling over to humans. Given the ability of bats to serve as natural reservoirs for coronaviruses, it has been speculated that bats may have been the origin of all three recent widespread respiratory illnesses among people, with other wildlife species likely serving as intermediary hosts (Zhou et al. 2020).

The SARS pandemic of 2003 was a respiratory illness that originated in China and spread to more than 8,000 people in 26 countries over an 8 -month period. It is believed to have been caused by a virus that spilled over from horseshoe bats (Rhinolophus spp.) to humans. Horseshoe bats are native to Asia, Europe, Africa, Australia, and Oceania. Several species of horseshoe bats in China can host the virus associated with SARS (SARS-CoV) in their bodies without being adversely affected by it. During the 
early 2000s, it is believed that the virus moved several times between animals and humans, with the animal hosts including horseshoe bats, palm civets (Paguma larvata, cat-like mammals native to East Asia, Southeast Asia, and Oceania), and pigs. How the virus was first transmitted to humans is still not well understood, but live wildlife markets have been implicated in promoting transmission to humans.

MERS is another widespread respiratory illness with zoonotic origins. Originally reported in Saudi Arabia in 2012, it spread across 27 countries. Dromedary camels (aka Arabian camels, Camelus dromedarius) are now known to be the primary zoonotic reservoir of the virus (MERS-CoV) that periodically facilitates transmission to humans. Scientists believe that bats may have been the original source of MERS as well, years ago before it jumped to camels.

Covid-19 is a third recent zoonotic coronavirus responsible for widespread human mortality. The origin of the virus that causes Covid-19 (SARS-CoV-2) has not yet been definitively identified, but there is speculation that it originated in horseshoe bats living in China, similar to SARS-CoV. We don't yet know whether the virus moved from bats to some other animal species before it was passed to people. There is some speculation that the virus may have passed from bats to pangolins before infecting humans and that live wildlife markets were involved.

\section{Why could persecution of bats lead to greater problems?}

The speculation that recent coronaviruses that caused pandemics may have originated in bats is causing persecution of bats worldwide in the name of protecting public health. This response is damagingly counterproductive.

Culling bats creates far more problems for human health than it solves. When left undisturbed in their wild habitats, bats pose little risk to human health. Although dozens of coronaviruses are able to survive within live wild bats, the risk of viruses moving from bats to humans under normal conditions is tiny. Bats have extremely active immune systems that enable them to carry pathogens without succumbing to infection. These viruses become a threat to humans only when the bats are stressed and in close proximity to humans. When left undisturbed, there is limited chance of wild bats transmitting any viruses they harbor to humans.

\section{How does bat conservation improve human health and livelihoods?}

Represented by more than 1,400 species, bats are one of the most diverse groups of mammals on the planet. Bats eat a variety of types of food, and in the process, they provide many ecological services to humans (Figure 2). Exterminating bats would result in ramifications harmful to people from an economic and health perspective.

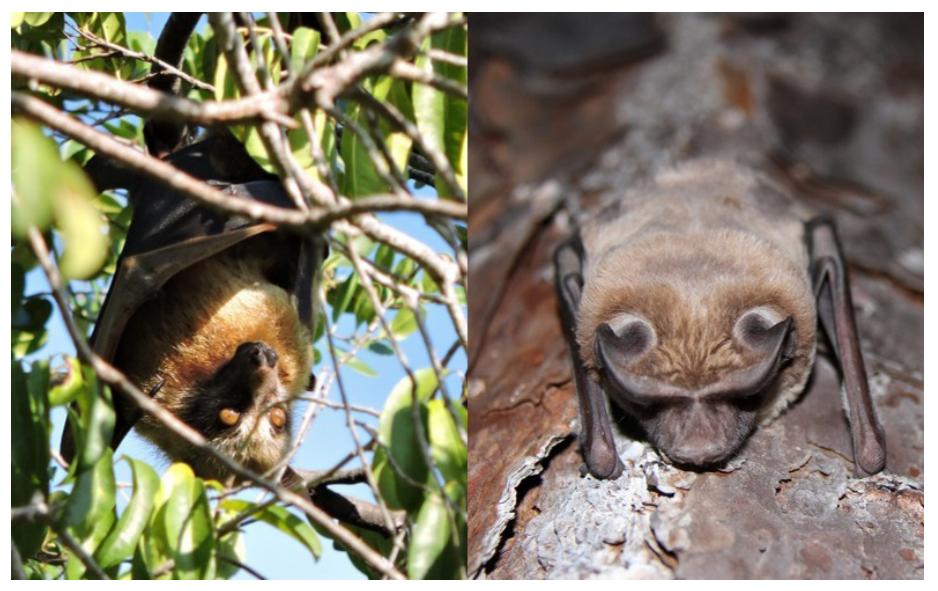

Figure 2. Bats make valuable contributions to natural ecosystems and people. Some, such as the Sulawesi flying fox (Acerodon celebensis, left), pollinate plants, producing many of the fruits we eat. Others, such as the Florida bonneted bat (Eumops floridanus, right), eat insects we consider pests.

Credits: Sheherazade (left), Kathleen Smith (right)

Many species of bats eat nectar and fruit, and in the process pollinate or disperse seeds of hundreds of species of fruit consumed by people including mangos, bananas, and guavas. Most bats are insectivorous, and they collectively consume millions of tons of insects a night. Nearly all the bats in the United States eat insects, many of which are considered pests to humans. It is estimated that bats save farmers, ranchers, and gardeners billions of dollars each year by naturally controlling pests of agricultural crops, reducing the cost of expensive pesticide applications while also reducing harm the chemicals could cause.

Eradicating bats would also have negative impacts on human health. Bats consume a variety of mosquitoes, which means they ultimately promote human health by reducing the ability of these insects to spread mosquito-borne diseases such as Zika, dengue, malaria, and chikungunya.

Our best strategy for reducing the likelihood of spillover of viruses from bats to humans, while benefitting from the help bats provide in controlling harmful insect pests, is to protect bats and their habitat. 


\section{Additional Information}

Bat Conservation International, http://www.batcon.org/

Banerjee, A., M. L. Baker, K. Kulcsar, V. Misra, R. Plowright, and K. Mossman. 2020. "Novel insights into immune systems of bats." Frontiers in Immunology 11: 26. https:// www.frontiersin.org/articles/10.3389/fimmu.2020.00026/ full

Boyles, J. G., P. M. Cryan, G. F. McCracken, and T. H. Kunz. 2011. "Economic importance of bats in agriculture." Science 332: 41-42. https://doi.org/10.1126/science.1201366

Ge, X., J. Li, X. Yang, et al. 2013. "Isolation and characterization of a bat SARS-like coronavirus that uses the ACE2 receptor." Nature 503: 535-538. https://doi.org/10.1038/ nature12711

Ober, H. K. 2008. Insect Pest Management Services Provided by Bats. WEC 245. Gainesville: University of Florida Institute of Food and Agricultural Sciences. https://edis.ifas. ufl.edu/uw289

Ober, H. K., and F. J. Mazzotti. 2008. Conservation of Bats in Florida. WEC247. Gainesville: University of Florida Institute of Food and Agricultural Sciences. https://edis.ifas. ufl.edu/uw291

Zhou, P., X. Yang, X. Wang, et al. 2020. "A pneumonia outbreak associated with a new coronavirus of probable bat origin." Nature 579: 270-273. https://doi.org/10.1038/ s41586-020-2012-7 